\title{
Representações de puérperas sobre o sistema alojamento conjunto: do abandono ao acolhimento*
}

\author{
MOTHERS' REPRESENTATION CONCERNING THE ROOMING-IN: FROM THEABANDONMENT TO THE \\ ACCEPTANCE
}

REPRESENTACIÓN DE LAS PUÉRPERAS ACERCA DEL ALOJAMIENTO CONJUNTO: DELABANDONO AL ACOGIMIENTO

\section{Alda Valéria Neves Soares ${ }^{1}$, Isília Aparecida Silva²}

\author{
Extraído de Soares AVN \\ Dissertação de \\ Mestrado apresentada à \\ EEUSP em 2000 \\ 1 Enfermeira Obstétrica \\ Chefe de Seção da \\ Unidade de Sistema de \\ Alojamento Conjunto \\ HU-USP \\ 2 Enfermeira Obstétrica \\ Professora Livre- \\ Docente do \\ Departamento de \\ Enfermagem Materno- \\ Infantil e Psiquiátrica da \\ EEUSP
}

\author{
RESUMO \\ O objetivo desse estudo foi \\ compreender a representação \\ social das puérperas acerca \\ do Alojamento Conjunto (AC). \\ Participaram 23 puérperas \\ internadas no $A C$ do \\ HU-USP. A análise dos \\ dados, obtidos por entrevistas \\ individuais e grupos focais, \\ baseou-se nas Representação \\ Sociais. Uma das \\ representações sobre sua \\ internação mostra sentimento \\ de medo, submissão às \\ rotinas institucionais e equipe \\ de saúde, um misto de \\ acomodação e resistência a \\ maneira impessoal como são \\ tratadas. A Hospitalização: do \\ abandono ao acolhimento, \\ indica como a disponibilidade \\ de interagir dos profissionais \\ atua como elemento de re- \\ significação das \\ representações de abandono e \\ indiferença sobre o \\ atendimento à mulher.

ABSTRACT
The Objective of this study
was understand the mothers'
social representation
concerning the rooming-in.
Population: 23 mothers
assisted in the University
Hospital of São Paulo
University. Data analysis was
obtained by individual and
group interviews, based on the
Social Representation. Results:
showed the feeling offear,
submission to the institutional
rules and health team's
routines, a mix of
accommodation and resistance
to the impersonal way these
women were been treated. It
also indicates, as the
availability of some
professionals to interact with
these women effectively, acts as
an element of re-significance of
the women's representations of
the abandonment and
indifference related to the care
given to them.

\section{ABSTRACT} \\ was understand the mothers \\ social representation \\ concerning the rooming-in. \\ Population: 23 mothers \\ University. Data analysis was \\ obtained by individual and \\ group interviews, based on the \\ Social Representation. Results: \\ showed the feeling of fear \\ submission to the institutional \\ routines, a mix of \\ accommodation and resistance \\ to the impersonal way thes \\ also indicates, as the \\ availability of some \\ professionals to interact with \\ an element of re-significance of \\ the women's representations of \\ indifference relat
given to them.
}

\section{RESUMEN}

El objetivo de este estudio fue el de comprender la representación social de las puérperas acerca del Alojamiento Conjunto (AC). Participaron 23 puérperas internadas en el AC del Hospital Universitario de la USP. El análisis de los datos, obtenidos por entrevistas individuales y grupos focales, fue realizada en base a los presupuestos de las Representaciones Sociales. Una de las representaciones de las mujeres sobre su internación hospitalar muestra el sentimiento de miedo, sumisión a las rutinas institucionales y al equipo de salud, una combinación entre acomodo y resistencia de manera muchas veces impersonal de la como son tratadas. La Hospitalización: del abandono al acogimiento, indica también, como la disponibilidad de algunos profesionales, en interactuar efectivamente con esas mujeres, actúa como elemento de re-significación de las representaciones de abandono e indiferencia que éstas cargam consigo, sobre la atención a la mujer.

PALABRAS-CLAVE

Alojamiento conjunto. Puerperio. Enfermeria materno-infantil

\section{PALAVRAS-CHAVE}

Alojamento conjunto. Puerpério.

Enfermagem materno-infantil.

\section{KEYWORDS}

Rooming-in care.

Puerperium.

Maternal-child nursing. 


\section{INTRODUÇÃO}

O nascimento, há algumas décadas, ocorria no ambiente domiciliar tendo a mulher a oportunidade de compartilhar com seus familiares esse momento. Contudo, a evolução econômica e social, aliada ao aprimoramento técnico-científico na área materno-infantil, fez com que as mulheres passassem a ser assistidas no momento do nascimento de seus bebês em instituições hospitalares. A institucionalização da assistência ao parto, percorreu o século passado imprimindo transformações na forma de atendimento à mulher e à criança, bem como à família.

As transformações no modelo assistencial à mãe e filho, atendeu em princípio, a necessidade de minimizar os riscos de agravos à saúde da mãe e da criança, resultando na implantação de berçários centralizados e decorrente separação da mãe e filho durante o período de internação.

Com a finalidade de novamente aproximar as mães de seus bebês, criou-se o Sistema Alojamento Conjunto que favorece a interação e a participação ativa dos pais nos cuidados ao recém nascido.

O Sistema Alojamento Conjunto é definido, segundo o Ministério da Saúde, como um sistema hospitalar em que o bebê sadio, logo após o nascimento, permanece ao lado da mãe, 24 horas por dia, num mesmo ambiente até alta hospitalar de ambos e que permite aos pais receberem orientações que os tornem aptos a prestar cuidados ao filho. Visa também, incentivar a amamentação, favorecer o vínculo entre os familiares, bem como, contribuir para a redução dos índices de infecção hospitalar ${ }^{(1)}$

Compreendemos que, para o funcionamento efetivo do Sistema Alojamento Conjunto, com atendimento de suas finalidades primeiras, é necessário que a equipe de saúde adote uma postura diferenciada, que demanda conhecimento sobre as necessidades de sua clientela, compromisso e envolvimento com a assistência a ser prestada à mãe e ao bebê.

O modelo vigente de assistência específica para a puérpera, enfatiza como fundamental, os aspectos educativos voltados para o desenvolvimento de habilidades maternas com a finalidade de instrumentalizar a mulher a cuidar do filho, responsabilizando-a por esse cuidado. Em especial nas instituições públicas, a mulher não opina sobre a assistência que lhe é prestada ou a modalidade de internação a que é submetida e, nem mesmo questionam o atendimento recebido. Será mera submissão ou satisfação de suas necessidades?

Assim, tendo o alojamento conjunto, quase duas décadas de implementação no Hospital Universitário, acreditamos estar em um momento em que seja necessário obter-se conhecimento de como as mulheres ali internadas e assistidas, vivenciam essa experiência, uma vez que acreditamos que estas devam ter percepções próprias ou construídas a partir de experiências de outras mulheres, acerca do período de internação hospitalar, na situação especial de maternidade.

Tanto a percepção da hospitalização, como a expectativa da vivência do puerpério, constituem-se em conteúdos que são assimilados pelas mulheres ao longo de sua vida, através de suas interações dotadas de significação própria e particular para cada mulher. Esses conceitos são elaborados socialmente, embora a realidade seja apreendida e construída de modo único pelas pessoas ${ }^{(2)}$

Assim temos como objetivo, compreender a representação das puérperas sobre o atendimento recebido durante sua internação no alojamento conjunto.

\section{DESENHO DA PESQUISA}

\section{Referencial te/órico - os pressupostos das representações sociais}

As questões que originam o estudo e sua natureza conduzem o desenvolvimento da investigação na abordagem qualitativa de pesquisa.

$\operatorname{Trivinos}^{(3)}$ relata que a pesquisa qualitativa tem o "ambiente natural" como fonte direta dos dados que envolve a obtenção dos mesmos de forma descritiva, através do contato direto do pesquisador que se preocupa com o processo e não simplesmente com o resultado.

Assim a escolha da metodologia qualitativa se justifica por permitir compreender a experiência da mulher que é atendida no alojamento conjunto, sob a ótica dos pressupostos das representações sociais.
Representações de puérperas sobre o sistema alojamento conjunto: do abandono ao acolhimento 
Alda Valéria Neves Soares Isília Aparecida Silva
Moscovici( ${ }^{(4)}$, traduz a representação social como sendo um conjunto de conceitos, afirmações, explicações dadas no cotidiano, que se configuram em uma teoria do senso comum. Ainda, para o autor, o sujeito é o criador do conhecimento a partir do que ele conhece, das experiências ocorridas em seu cotidiano e do valor dado a estas experiências vividas. Essa condição de criador da realidade e conhecimento, nunca é deslocada da historicidade e do contexto social de seu mundo.

Moscovici ${ }^{(5)}$ considera que na sociedade contemporânea coexistem dois universos distintos de pensamentos: os universos consensuais e os universos reificados.

Nos universos consensuais a sociedade se vê como um grupo feito de indivíduos de igual valor, expressando livremente suas opiniões, respostas e teorias para todos os problemas, ocorrendo neste universo as teorias do senso comum, sendo o universo reificado, a instância na qual se produzem e circula as ciências e o pensamento erudito.

Spink $^{(6)}$ coloca numa perspectiva temporal a existência de três tempos na elaboração da representação social, sendo elas:

- tempo curto da interação, que tem por foco a funcionalidade das representações, no aqui-agora;

- tempo vivido, compreendendo o processo de socialização tendo a influência do grupo social ao qual o indivíduo pertence;

- tempo longo, compreendido pelo domínio das memórias coletivas, onde estão depositados os conteúdos culturais acumulativos de nossa sociedade.

O estudo da representações sociais está voltado para o conteúdo dessas comunicações que se manifestam em palavras, sentimentos e condutas sendo estas, medidas pela linguagem que é tomada como forma de conhecimento e de interação social ${ }^{(7)}$.

Para esse estudo, estamos considerando o tempo curto do contexto das mulheres, estruturado nas relações do aqui-agora vivenciadas na unidade de Alojamento Conjunto onde elas são atendidas.
O cenário da investigação, obtenção $e$ análise dos dados

\section{$O$ contexto}

Esta pesquisa foi desenvolvida no Hospital Universitário da Universidade de São Paulo (HU-USP), na unidade de Alojamento Conjunto (AC), no qual a mulher é internada cerca de uma hora após o parto. A transferência do recém-nascido, do berçário para o $\mathrm{AC}$, pode ser feita a qualquer momento após seis horas de vida, dependendo tanto das suas condições clínicas, quanto das condições maternas para recebê-lo. Na unidade, a mulher recebe orientações sobre o autocuidado e o cuidado com o recém-nascido. Esse conteúdo é passado através de aulas expositivas divididas em duas manhãs, durante o período em que a puérpera permanece internada, que atinge cerca de 60 horas de pós-parto, no mínimo.

\section{Obtenção dos dados}

Participaram do estudo, puérperas que não apresentaram intercorrências clínicas ou obstétricas, na gravidez e puerpério, e que permaneceram com os seus filhos durante a sua internação no AC. Após consulta aos prontuários, as mulheres que atendiam aos requesitos mencionados, eram convidadas a colaborar para a pesquisa, sendo abordadas no último dia de internação, após tomarem conhecimento da sua alta hospitalar. As mesmas foram informadas dos objetivos e finalidades da pesquisa e dos demais aspectos relativos às questões éticas. Ao aceitarem fazer parte do estudo, estas eram conduzidas a uma sala em que era possível manter-se a privacidade para a realização da coleta dos dados. Iniciamos a coleta de dados com a técnica de entrevista individual, o que foi realizado com três puérperas. Após estas, consideramos que as mulheres não se sentiam a vontade para falar sobre o tema, o que nos levou a optar pela técnica de grupos focais. Assim, colhemos novos dados com outras 20 puérperas, as quais foram dividas em quatro grupos focais. A definição do número de 23 participantes foi determinado pela saturação dos dados obtidos. Para motivar o discurso das mulheres no grupo focal, iniciamos com uma questão norteadora: Conte-me como foi para vocês a experiência de internação aqui no Alojamento Conjunto. As entrevistas e grupos focais foram gravadas com o consentimento livre e esclarecido 
das mulheres, em documento assinado por elas, seguindo as normas legais de ética em pesquisa.

\section{$A$ análise dos dados}

Aplicamos o método de organização dos dados e captação dos sentidos ali contidos, segundo o método de Taylor; Bogdan ${ }^{(8)}$, o qual é uma forma sistemática de desenvolver e aprimorar a interpretação dos dados, em que são feitas inúmeras leituras do material transcrito das falas originais em busca de temas e idéias contidas nos discursos, procedendose ao agrupamento destas, de acordo com o conteúdo expresso nas mesmas.

\section{RESULTADOS}

\section{O que as mulheres nos têm a dizer}

A partir das falas das mulheres participantes do estudo, identificamos a representação a qual nominamos de $A$ Hospitalização: do abandono ao acolhimento, que expressa a vivência da mulher na busca da assistência institucionalizada ao parto, que para elas se traduz, em princípio, em submeter-se ao evento da hospitalização. Uma submissão, não só aos aspectos burocráticos, que a deixam insegura quanto a possibilidade de conseguir a vaga para ser internada,

Inclusive foi até difícil entrar, eles exigem vários documentos, mas como eu sou do bairro foi até fácil (Ametista).

como também, significa submeter-se a um mundo desconhecido, e representado por ela, em princípio, como um lugar de abandono.

\footnotetext{
Eu tinha medo de vir para o hospital porque largava a gente, horas e horas, não tava nem aí... (Rubi).
}

\section{Um lugar de abandono}

Ao ter que vivenciar a hospitalização, emergem sentimentos de medo, sofrimento e abandono, que integram e permeiam a representação que a mulher constrói ao longo de sua vida, partilhando a experiência de seus pares dentro do seu grupo de pertença.

Segundo Silva ${ }^{(2)}$, a experiência da parturição para a mulher é caracterizada pelo sentimento do medo, não apenas pelo risco e sofrimento físico que julga estar exposta no parto, mas também pelo receio de não encon- trar acolhida dos profissionais que a assistirão. Segundo a autora, o mundo da mulher é povoado pela angústia de ser maltratada e abandonada por uma equipe que lhe imponha restrições físicas e castigos, caso ela não consiga ser forte para suportar calada as temidas dores do parto e também ajudar adequadamente seu filho a nascer.

Eu imaginava (...) do que as pessoas falam, de como é maternidade, que quando eu chegasse ia ficar com dor, e elas não iam ligar para mim (Safira).

Percebemos que as mulheres em seu ambiente social e cultural atribuem um sentimento de dor em relação ao parto e de abandono por parte dos profissionais que the oferecem assistência, sendo esta a concepção presente no entendimento das puérperas sobre a sua hospitalização.

Simões; Souza ${ }^{(9)}$ comentam que a mulher compreende sua vivência de parturição como angustiante e temerosa, porque a partir do momento em que é internada na maternidade, não tem mais controle da situação, tudo se revela como imprevisível e não familiar.

A institucionalização do parto, com o seu aparato técnico, com as normas e rotinas hospitalares, a pouca ou nenhuma participação da família neste processo, são fatores que contribuem para reiterar as representações de sofrimento e abandono que as mulheres têm, baseadas no conhecimento consensual, e maximizam o medo do desconhecido que é o parto ocorrido no ambiente hospitalar.

Estabelecidas as relações de poder desde o princípio da internação a mulher submetese para poder ter a garantia de atendimento, ao que Pamplona ${ }^{(10)}$, confirma ao colocar que a mulher tende a assumir a atitude passiva e submissa frente aos aparelhos institucionais e aos profissionais, por atribuir a autoridade a esses atores sociais, comportamento este, reforçado pela sua condição de submissão dentro dos diversos contextos sociais em que se insere.

A condição de aceitação das normas e regras institucionais se estende ao período de internação no pós-parto, em que o papel materno, imprime a figura emblemática da responsabilidade da mulher em cuidar do filho e sustenta a autoridade da instituição em cobrar-lhe as habilidades de atender às necessidades do RN.
Representações de puérperas sobre o sistema alojamento conjunto: do abandono ao acolhimento 
Alda Valéria Neves Soares Isília Aparecida Silva
No entanto, o medo tão presente nas falas das puérperas e sua condição de submissão aos profissionais começa a ser dissipado, ou melhor, vai sendo amenizado a partir das interações que se estabelecem no cotidiano da clínica. A ajuda que lhe é oferecida pelos profissionais que a assistem, quando se dá a partir de um relacionamento efetivo, faz com que a mulher re-elabore suas representação, percebendo a experiência atual, no aqui-agora do contexto de hospitalização para o nascimento de seu filho, diferente da expectativa criada no tempo vivido, que precedia ao evento da internação.

Tá sendo bom, uma experiência boa, totalmente diferente do que eu imaginava. Para mim ia ser um bicho de 90 cabeças (Ágata).

Longe da família e sem o companheiro ao seu lado ou mesmo alguém que lhe seja familiar a mulher trás consigo um receio que gradativamente ameniza ao receber ajuda, tendo a experiência de não estar só. A partir desse momento a puérpera passa a re-significar suas representações sobre sua hospitalização, na medida que vivencia uma experiência em que recebe ajuda, atenção, elementos estes que não faziam parte de seu universo representacional anterior.

Tive muita ajuda, de pessoas estranhas de que eu nunca vi, que me ajudaram melhor do que se fosse alguém conhecido. Para mim foi muito bom (Ágata).

Nesse sentido ela passa a perceber o hospital como um lugar de ajuda:

\section{- Recebendo ajuda}

As mulheres apresentam a necessidade de serem auxiliadas para o atendimento de suas necessidades básicas e para iniciar sua relação com o filho. Necessitam de ajuda para cuidar da criança e estímulo para sentirem-se seguras no papel materno. Assim, a representação da hospitalização como lugar de abandono, passa a dar lugar a outro universo, em que recebendo ajuda, ela re-qualifica a experiência de estar hospitalizada, quando se sente atendida em suas necessidades.

É meu primeiro aqui. Quando eu subi, nossa, as enfermeiras super atenciosas, vem todo momento dentro do quarto ver se tá precisando de alguma coisa, se tá com dor, eu imaginava que tivesse que ficar chamando (Safira).
A partir da identificação da existência de que há alguém para ajudá-la, a mulher modifica sua percepção, ainda que localize a re-significação para esta experiência específica, no aqui-agora no AC.

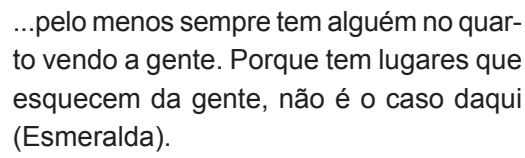

Ao perceber que existe alguém do seu lado para lhe ajudar, as mulheres não se percebem sós, e isso as faz se sentirem mais seguras em relação ao atendimento que recebem, eliminando a sensação de abandono que a acompanha e amedronta em sua hospitalização.

Bittes Júnior ${ }^{(11)}$ afirma que é a partir da percepção de necessidade de cuidados que os pacientes vivenciam na hospitalização o início do processo de interação com o outro que é o elemento ajudador, o que implica, a nosso ver na compreensão por parte do profissional, de que não basta a presteza técnica, mas é necessária a habilidade de interagir.

Assim, neste estudo, percebemos que o cuidado não representa apenas a assistência ao parto e aos eventos involutivos do puerpério, mas a assistência deve ser mais ampla, envolvendo a atenção aos aspectos subjetivos maternos, o que deve apontar para além da dimensão obstétrica.

Quando existe a combinação entre o elemento ajudador e a ajuda concreta ocorrida, a puérpera passa a representar de forma positiva o serviço oferecido.

\footnotetext{
Para mim é completamente novo. Quando eu fui dar de mamar na primeira mamada tinha a enfermeira do berçário que ficou me ajudando(...) para mim foi bem proveitoso (Pérola).
}

Assim, na experiência de ser mãe, a mulher independente de ser primípara ou multípara, identifica a necessidade de ter alguém do seu lado afim de lhe oferecer alguma ajuda, não apenas no cuidado direto, prestado à elas, mas também quando esse cuidado a beneficia indiretamente;

Tem hospital que as enfermeira nem ligam para as crianças, aqui se a gente tá almoçando e o bebê chorando, elas já pegam, enrolam, vamos dar um passeinho? Terminou mãezinha? (Opala). 
$\mathrm{Ou}$, quando percebe seu filho recebendo a atenção.

Aqui elas pegam o recém-nascido veêm se tá sujo, limpam. Trocam de roupinha. Não tenho do que reclamar (Opala).

Sentir-se ajudada representa para a puérpera segurança, tranqüilidade e amparo, o que é percebida e valorizada pelas puérperas como uma atenção individualizada no seu atendimento.

As oportunidades de interação com os profissionais também dizem respeito a confiança estabelecida no serviço, quando a mulher sente que tem diálogo com a equipe que lhe dá explicações acerca de seu estado de saúde ou de seu filho.

Uma coisa boa aqui é que eles não mentem o que a criança têm (Rubi).

É interessante perceber, que embora o foco do estudo se concentre na vivência da mulher no AC, portanto na fase puerperal, esta não dissocia sua representação da hospitalização, dos diferentes ambientes clínicos pelo qual passa. A sua experiência apresenta uma linearidade que faz com que ela perceba a hospitalização desde sua internação no Centro Obstétrico até sua alta no $\mathrm{AC}$, em que todos os eventos são parte do todo, em que a interação interpessoal que ocorre entre a mulher e seus cuidadores, é a fonte principal de re-significação da representação de "abandono", para sentir-se cuidada ou atendida.

Aí iam lá e tiravam o nenê e só. Mas não, foi o tempo todo em cima de mim tentando me acalmar, pedindo para mim ter paciência, dando sempre uma palavra de conforto (Safira).

Dessa forma, a partir da constatação da ajuda recebida e de que não está só, a mulher toma os elementos identificados na ajuda, como indicadores de qualidade para a assistência que recebe e passa a interpretar sua experiência de forma diferente daquela imagem que construiu ao ouvir outras mulheres em sua comunidade, ou mesmo, a partir de experiências anteriores.

\section{- Recebendo esclarecimentos}

O fato das puérperas terem suas dúvidas esclarecidas durante a internação pelos profissionais que lhe assistem, também é perce- bida como uma forma de ajuda e que constitui-se em elemento qualificador da assistência e de reelaboração de sua representação acerca da hospitalização.

É tem bastante coisa que agora eles estão ensinando e assim é bom para gente. Perguntas que a gente não tem para quem perguntar eles estão explicando nas aulinhas. Tem muitas dúvidas que a gente tinha também. Eu mesmo tinha e agora já foi explicado (Rubi).

\section{- Atendida prontamente}

Outro elemento de qualificação é construído em função da percepção que as puérperas tem do número de pessoas envolvidas na assistência que é dispensada a ela e ao recém-nascido.

\section{De manhã eu acho que o atendimento é bem melhor que a tarde. É assim, a tarde tem menos pessoas (Esmeralda).}

Verificamos com esse depoimento que a dinâmica da instituição hospitalar constituída pela visita médica, coleta de exames, atividades de promoção de higiene, que ocorrem predominantemente pela manhã, interfere na percepção das pacientes sobre o atendimento que recebem.

Sabemos que na maioria dos hospitais há um maior contingente de profissionais na assistência durante o período matutino, ocorrendo o mesmo em nossa instituição.

As visitas médicas obstétrica e pediátrica ocorrem pela manhã e, juntamente com as atividades dos alunos de medicina e de enfermagem, concorrem para que a puérpera interprete que o número maior de pessoas envolvidas na assistência lhe proporcione uma maior rapidez no atendimento, resultando na representação de melhor assistência de manhã do que o efetuado em outro período.

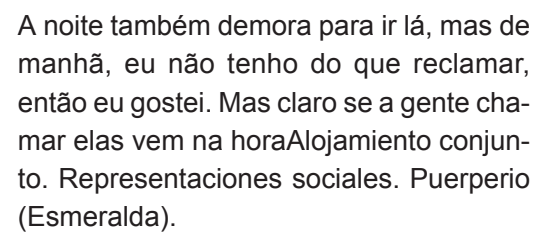

Percebemos que a presteza no atendimento, a constatação de que há realmente alguém para lhe atender, assume importância para a mulher, uma vez que a rapidez no atendimento é interpretado como um cuidado para com ela e com seu filho, o que torna o local, antes desconhecido, em ambiente seguro.
Representações de puérperas sobre o sistema alojamento conjunto: do abandono ao acolhimento 
Alda Valéria Neves Soares Isília Aparecida Silva
Se a gente aperta a campainha, vem correndo atender a gente (Pérola).

Essa segurança é tão necessária à mulher, que ela relata que voltaria a instituição em uma nova gravidez.

Tanto que eu quis vim ter aqui de novo. Não me leva para outro, quero ter lá. Aqui eu fui sempre bem tratada, em todos os momentos, na hora que eu preciso é só chamar, rapidamente alguém vem(Cristal).

\section{- Atendida sem educação:} "sendo maltratada"

No entanto, mesmo recebendo todo o tipo de ajuda, esta não se qualifica como tal quando a mulher não encontra no profissional uma pessoa com disponibilidade de vê-la como pessoa e que a trate com atenção, carinho, expresse preocupação. Na ausência desses elementos as mulheres se sentem fragilizadas, assustadas, perdidas como referido na fala de uma delas:

Porque a gente não podia chamar ninguém que vinha todo mundo de cara feia, aquela coisa assim que assusta, talvez se fosse de outra maneira se começasse tudo no Domingo a gente não se sentisse tão perdida. Eu me senti perdida(Turmalina).

O mau atendimento é qualificado por meio de sensações envolvendo sofrimento, solidão e desatenção.

Toda vez que precisei, ajudaram, nunca faltaram não, mas não com a boa vontade que deveria ser... (Água Marinha).

As pacientes ao perceberem que os profissionais as assistem de forma desatenciosa e descompromissada, acabam desqualificando o atendimento que recebem

Afinal de contas eu e a... fizemos cesárea e é muito dor... para mim foi um suplício (Turmalina).

Ratificando este aspecto, Maldonado ${ }^{(12)}$ afirma que o mundo do hospital se apresenta de modo diferente aos olhos do profissional da saúde e aos olhos da paciente.

Quando o profissional não percebe, não identifica os problemas que as pacientes possuem, a interação entre paciente e cuidador não é estabelecida, prejudicando o processo de hospitalização e dificultando a excelência do cuidado que representa o bem estar do paciente.

\section{- Atendida com educação:} "tratada como gente"

A disponibilidade interna manifesta do profissional através de suas atitudes dirigidas ao paciente é considerada pelos próprios profissionais o elemento qualificador da assistência. É esse atributo que o coloca em relação com o paciente possibilitando a comunicação interpessoal. Dessa maneira, é possível o profissional captar, mais precisamente, as necessidades de sua clientela $^{(13)}$. No caso das puérperas deste estudo, também foi possível perceber este fenômeno como indicador de qualificação da assistência e elemento de re-significação de suas representações:

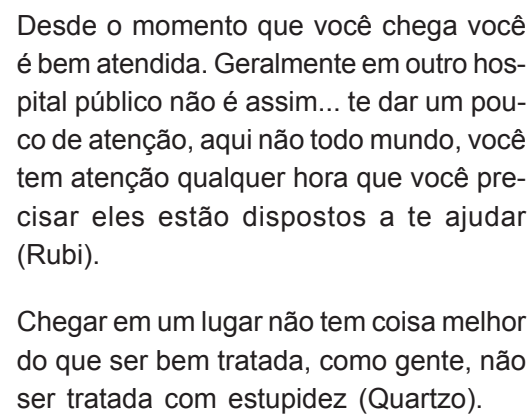

Chegar em um lugar não tem coisa melhor do que ser bem tratada, como gente, não ser tratada com estupidez (Quartzo).

Assim a disponibilidade do profissional, expressa através de comunicação verbal e não verbal, resulta em oportunidade para orientações e acompanhamento das dúvidas das puérperas, influenciando diretamente a qualidade de sua experiência de hospitalização.

Para Stefanelli ${ }^{(14)}$ a comunicação media toda a ação da enfermeira que deve ter, não só consciência do fato, mas também conhecimento deste processo e de todos os elementos a ele inerentes. Dessa forma, ela pode utilizar deste processo em sua prática, abrindo a possibilidade para que a paciente a considere como um elemento de ajuda capaz e eficiente, pois é um outro ser humano, com quem poderá interagir, dividindo seu sofrimento e compartilhando suas idéias.

Nesse sentido, em seu estudo, Bittes Júnior ${ }^{(11)}$ constatou que o cliente se sente bem tratado e considera o cuidador um bom profissional com boa vontade, interessado e envolvido, se souber que esse mesmo profissional está disponível para atendê-lo. E mais, estar disponível é ter paciência.

Neste processo elas verbalizam o que compõem o ser "bem atendidas": 
Atenção, boa vontade, respeito, ser tratada como gente, porque pertenço a comunidade que é atendida por este hospital, pago meus impostos e tenho direito a este atendimento (Turmalina).

Nesse aspecto Bittes Júnior ${ }^{(11)}$ encontrou em sua pesquisa que o paciente busca estabelecer um relacionamento interpessoal com o cuidador" e que no cuidado realizado deve haver amor, carinho, educação, paciência na percepção dos mesmos.

\begin{abstract}
Elas, não são só enfermeiras, elas passam assim segurança também. Parece que elas estão sentindo o que a gente tá sentindo ali na hora. Não é aquelas enfermeiras que vem dá injeção e pronto: fim do meu trabalho e pronto já cumpri. Elas conversam com a gente tem uma dúvida elas tem paciência de explicar, todas as enfermeiras me deram atenção para dar e vender. E assim de parar e conversar mesmo, e não assim de responder e já sair respondendo tá bom e já ir embora. Ficar mesmo e dar atenção eu acho que isso é ser bem tratada. $1^{\circ}$ lugar com educação... (Berilo).
\end{abstract}

Assim verificamos que quando o cuidado compõem-se de elementos como atenção, paciência, tempo para ouvir, a mulher apreende estes elementos e é capaz de interagir com o cuidador, sentindo-se segura e qualificando o atendimento.

Assim, percebemos que as puérperas analisam os recursos humanos existentes, tanto em número, como também, a relação constituída entre o profissional e o paciente no momento em que o cuidado é oferecido e em que tempo é realizado.

Na vivência de sua hospitalização as mulheres mais uma vez interagem, reformulam esse novo conceito de atendimento e avaliam-no compondo uma nova representação do que é ser atendida no serviço que buscaram assistência.

A mulher valoriza em sua fala, uma assistência que seja voltada para o seu cuidar. Contudo esse cuidado tão valorizado pela mulher deve conter os componentes como atenção, paciência e outros já citados anteriormente afim de proporcionar-lhe uma experiência positiva e segura.

Neste processo de hospitalização na unidade de $\mathrm{AC}$ as puérperas incorporam ao seu repertório novos conteúdos emergidos da vivência do seu atendimento no HU-USP. Isto é percebido nas falas das puérperas que nos repassam as informações veículadas em sua comunidade, transmitidas pelas mulheres que já passaram pela experiência de serem atendidas no AC.

Na minha rua quatro vizinhas já tiveram
filhos aqui nesta maternidade inclusive
uma que teve o último nenê agora, Sába-
do passado. Todas falaram muito bem da
parte de poder estar junto das crianças,
de poder estar olhando, de ser bem aten-
dida, do lugar que é muito limpo e se tiver
algum problema, alguma complicação tem
recursos para cuidar... O meu médico
apesar de ser municipal também falou que
era um lugar muito bom (Turmalina).

Verificamos assim que a veiculação do pensamento e da representação se dá através da comunicação dos sujeitos que após sua vivência, reconstituem, retocam, ou modificam seu pensamento, imprimindo suas impressões na representação( ${ }^{(15)}$.

\section{CONSIDERAÇÕES FINAIS}

A proposta deste estudo, de conhecer as representações sociais de mulheres sobre a sua vivência no Alojamento Conjunto do HUUSP foi desenvolvida, fundamentalmente, a partir do pensamento de que, compreendendo mesmo que parte da vivência das mães, poderíamos conhecer a qualidade e o sentido da assistência oferecida a elas.

Alguns elementos deste estudo apontam questões que devem ser refletidas pelo profissional que atua nessa área, buscando assim elementos facilitadores que possam fazer dele, o profissional, mediador ou facilitador da experiência que essas mulheres têm nas instituições de saúde, em especial, na fase do nascimento de seus filhos.

Assim, embora este estudo não tenha verticalizado na questão das construções das representações sociais e apenas tenha se limitado a apontar temas constituintes das representações mais significativas e evidenciadas a partir das falas dessas mulheres, os resultados aqui emergidos apontam recortes da experiência materna que merecem ser aprofundados em estudos posteriores.

O evento do parto e nascimento, para essas mulheres, indica o quanto a experiência
Representações de puérperas sobre o sistema alojamento conjunto: do abandono ao acolhimento 
Alda Valéria Neves Soares Isília Aparecida Silva da hospitalização ainda se mostra aos seus olhos como uma ameaça à dignidade feminina. A representação da hospitalização como uma experiência de um lugar de abandono onde elas estarão submetidas a procedimentos e ao domínio de profissionais, traduzindo, assim, o quanto a clientela tem sido subjugada a autoridade do saber, sem ter espaço para opinar sobre o cuidado que recebe e mesmo sobre as decisões que são tomadas em relação aos processos terapêuticos a que é submetida.

Embora na falas dessas mulheres perceba-se que é veiculada na comunidade uma interpretação positiva da experiência de outras mulheres atendidas na mesma Instituição, na representação sobre o processo de hospitalização, ainda prevalece a memória coletiva do conjunto de experiências transmitidas pelas mulheres que vivenciaram o atendimento ao seu parto e puerpério de forma negativa, nas diversas instituições em que já foram atendidas.

Neste estudo, o fenômeno da internação é um dado presente e marcante, fazendo com que essas mulheres, embora questionadas sobre sua experiência no Sistema de Alojamento Conjunto, se reportassem aos elementos de interação ocorridos em toda a sua trajetória de atendimento e, ao indicarem os elementos de qualificação da assistência recebida, se referiam aos processos de interação interpessoal ocorridos desde sua entrada no hospital.

É possível perceber pelos temas apresentados, o quão importante é o papel do profissional na re-significação das representações dessas mulheres.

É preciso considerar que os pontos fundamentais da assistência, do sistema de Alojamento Conjunto, não estão nas rotinas e instalações físicas que aproximam mãe e criança nas dimensões espaço-temporal. O grande diferencial apontado está na relação entre o profissional e a paciente, nas situações em que este se coloca disponível para ajudar a mulher a vivenciar essa experiência. As interações interpessoais são os verdadeiros instrumentos que auxiliam as mulheres a percorrerem a experiência da hospitalização.

\section{REFERÊNCIAS}

(1) Brasil. Portaria $n^{0} .1016$, de 26 de agosto de 1993. Dispõe sobre as normas básicas de alojamento conjunto. Diário Oficial da União, Brasília, 01 set. 1993.

(2) Silva IA. Amamentar: uma questão de assumir riscos ou garantir benefícios. São Paulo: Robe; 1997.

(3) Trivinos ANS. Introdução á pesquisa em ciências sociais: a pesquisa qualitativa em educação. São Paulo: Atlas; 1992.

(4) Moscovici S. A representação social da psicanálise. Rio Janeiro: Zahar; 1978.

(5) Moscovici S. Psicologia social: influencia y cambio de actitudes, individuos y grupos. Barcelona:Paidos; 1991.

(6) Spink MJP, organizador. O conhecimento cotidiano. São Paulo: Brasiliense; 1993.

(7) Minayo MCS. O desafio do conhecimento: pesquisa qualitativa em saúde. São Paulo: Hucitec-Abrasco; 1993.

(8) Taylor SJ, Bogdan RC, editors. Introduction to qualitative research methods: the search for meanings. $2^{\text {nd }}$. ed. New York: John Wiley \& Sons; 1984. Working with data; 123-45.
(9) Simões SMF, Souza IEO. Parturição: vivência de mulheres. Texto Contexto Enferm 1997; (6):168-80

(10) Pamplona V. Mulher, parto e psicodrama. São Paulo: Ágora; 1990.

(11) Bittes Júnior A. O movimento pendular do significado do cuidado para o paciente. [dissertação] São Paulo (SP): Escola de Enfermagem da USP; 1996.

(12) Maldonado MT. Psicologia da gravidez. Petrópolis: Vozes; 1988.

(13) Silva IA. Construindo perspectivas sobre a assistência em amamentação: um processo internacional. [tese] São Paulo (SP): Escola de Enfermagem da USP; 1999.

(14) Stefanelli MC. Comunicação com paciente: teoria e ensino. São Paulo: Robe; 1993.

(15) Sá CP. Representações sociais: o conceito e o estado atual da teoria; In: Spink MJP, editor. O conhecimento no cotidiano. São Paulo: Brasiliense; 1993. p.465-78. 